\title{
Urinary Bladder Tumor Antigen
}

National Cancer Institute

\section{Source}

National Cancer Institute. Urinary Bladder Tumor Antigen. NCI Thesaurus. Code C1801.

Bladder tumor associated antigen is a human complement factor $\mathrm{H}$-related protein (hCFHrp), a glycoprotein produced by cancer cells and macrophages but not by normal epithelia. In cell culture, hCFHrp was shown to be produced by several human bladder cancer cell lines, but not by normal epithelial cell lines. By interaction with complement factor C3b, hCFH serves to inhibit the formation of a membrane attack complex, thereby preventing cell lysis. Production of bladder tumor associated antigen may confer a selective growth advantage to cancer cells in vivo by allowing the cells to evade the host immune system. Approved by FDA as a tumor marker for screening test for transitional cell carcinoma. 